\title{
INFORMATION AND COMMUNICATION TECHNOLOGY BASED MODEL FOR DEMATERIALIZATION OF ACADEMIC CERTIFICATES FOR INDIAN EDUCATIONAL SYSTEM
}

\author{
Ramakrishnan Raman, Dhanya Pramod and Vijayakumar Bharathi \\ Symbiosis Centre for Information Technology, \\ Faculty of Computer Studies, Symbiosis International University, Pune, India
}

Received 2013-11-10; Revised 2013-11-11; Accepted 2013-12-03

\begin{abstract}
Information Communication Technology (ICT) can integrate all facets of academic business. Though some schools and Universities in India have attempted to digitize some or many parts of their business processes, awarding the final academic credentials/certificates is still paper based. The printed paper certificates is a huge cause of concern for security and reliability, as it gives opportunity to fraudsters to exploit the system and create fabricated certificate, as there is no easy mechanism available to verify and check the authenticity of the certificate. Secondly the present system is not green and environment friendly. This study proposes an Information Communication Technology (ICT) based model for dematerialization of academic certificates for Indian educational system.
\end{abstract}

Keywords: ICT, Dematerialization, Indian Educational System, Academic Certificate, Challenges, Security and Reliability

\section{INTRODUCTION}

In present day, Indian educational institutions offer all academic certificates to students who pursue their schooling, undergraduate, graduate, doctoral and postdoctoral programs in the form of paper based printed documents. There is no standard format specified by any governing body that regulates school education or higher education in India. There are plethora number of regulatory bodies which govern and regulate different domain of education, like All India Council for Technical Education (AICTE),Universities Grant Commission (UGC), Bar Accessory Room (BAR) council, Medical Council of India (MCI), Indian Nursing Council (INC), Distance Education Council (DEC) and so on at the undergraduate and post graduate Level. There are also different governing bodies and regulatory agencies at the school level which include International Baccalaureate (IB), Central Board of Secondary Education (CBSE), Indian Certificate Secondary Education (ICSE), Indian School Certificate
(ISC), Certificate for Vocational Education (CVE) and also the State Boards which are many in number, have different regulations as decided by the respective state regulatory bodies for school education in India. This system creates a lot in convince for certificate verification when a student opts to go for higher education or plans to join a company or applies for a loan in an financial institution. There are agencies which do this job of certificate verification as their main stream business in India. In today's context, if a person misses a certificates, he/she has to go through complex bureaucratic processes in order to get a duplicate certificate. Another huge cause of concern is due to fraudsters who exploit this system and create fabricated certificate, as there is no easy mechanism available to verify or check the authenticity. Also as paper based certificates is being used, the current system is also not green and environment friendly. According to Phillip (2005) considerable progress has been made in the provision of higher education in India. In 1950-51 Corresponding Author:Ramakrishnan Raman, Symbiosis Centre for Information Technology, Faculty of Computer Studies, Symbiosis International University, Pune, India 
India had only 27 universities or deemed universities. As things stand today this number has increased to 400 and vast improvements have also been made in generating gender equality in access to higher education. But a single central point control for regulating standards for certificate pattern, design and code does not exist. This study proposes an Information Communication Technology (ICT) based model for dematerialization of academic certificates for Indian educational system. The primary objective of proposed model is to ensure certificates are accessed by individuals in a dematerialized format and the same is standardized across which can facilitate easy verification. The secondary objective of the paper is to of derive environmental benefits with the replacement of traditional paper based system with ICT based model for the dematerialization of certificates.

\section{OVERVIEW OF EXISITING SYSTEM}

India has over 550 million people below the age of 25 years. According to Census figures, over $32 \%$ of the 1.1 billion population is between the age group 0-14. This indicates that the number of people in India eligible for primary and secondary education alone exceeds the entire population of the United States of America. Since these students will be seeking higher education in India over the next decade, it illustrates the sheer size of the Indian education market. Presently about 11 million students are in the Higher Education system. This represents just $11 \%$ of the of the 17-23 year old population. The government hopes to increase this to atleast $21 \%$ by 2017 . With the emergence of India as a knowledge-based economy, human capital has now become its major strength. This has put the spotlight on severe inadequacies of India's infrastructure for delivery of education, particularly higher and vocational education (IGR, 2012). The existing system and processes for verifying certificate authenticity is complex, as there is no universal standard. The system works in isolation and is fully paper based. The regulatory authorities have not specified any universal standards for-the pattern of certificate, the formats and the identification code. This makes every educational institute to have different types, designs and coding standards to be adopted as per their whims and fancies while they issue a certificate at the school or at the college level. There is no central repository to check and verify the correctness of data and this makes the job of verification a herculean task. A case example: When a student completes his schooling from a school which is governed by the state regulatory body (state board) from a specific state in India, say Assam and then opts to do his under graduate program from another state in India, say Maharashtra, then in the process of giving admission, the undergraduate institute has to verify the certificate of the student at the institute level and further at the University level. Currently this process is just based on trust. The institute verifies the paper based document given by the student. The authentication is taken just based on the document submitted by the student. With the current developments and the technology aids available, it is very easy for someone to prepare a spurious document and secure admission for the undergraduate program. If the institute offering admission to the student choses to communicate with the said school, then the process would take several months and hence it not practically feasible. Adding to the complexity is the number of boards which offer high school education - which are many in number. Hence the current system is purely based on manual processes. The place where technology is currently being used, to a limited extend and in limited number of institutions, is to communicate with the students via email and possibly asking them to send their certificates in a digital format by scanning the same. This problem is carried forward when the student opts to go for a higher education in the same university or any other and also when he/she opts to take up a job. The employers generally verify the academic credentials by themselves or through third party, who in turn contact the educational institute or the university to check the authenticity of the documents. This is a time consuming process as it is person based and not a process based mechanism for verification.

\section{THE CONCEPT OF DEMATERIALIZATION}

In order to mitigate the risks associated with issues related to maintaining documents, credentials, certificates in paper format, dematerialization concept was introduced in India, first in the Indian Financial Market (Singh, 2011). Dematerialisation or Demat in short is the process through which a paper based certificate gets converted to electronic format which is maintained in an account. In the financial market, a paper based share certificate gets converted to electronic format which is maintained with the Depository Participant. Depository is the body which is responsible for storing and maintaining investor's 
securities in demat or electronic format. In India there are two depositories i.e., National Securities Depository Limited (NSDL) and Central Depository Services India Limited (CDSL). Depository Participant (DP) is the market intermediary through which investors can avail the depository services. Depository Participant provides financial services (BSL, 2013).

A study identified that dematerialization implementation in the administration process as an innovative outcome of ICT adoption in organizations. It was found that dematerialization enabled energy conservation leading to lower environmental impact in other words dematerialized system will have a positive impact from an environment perspective and reap greater benefits (Mirabella et al., 2013). The diffusion and use of ICT can lead to positive environmental impacts through the substitution of information goods for material goods. The direct impact is on the resource use and pollution control, while the indirect influence life styles, value systems (Berkhout and Hertin, 2004). The synergy between the Internet and ICT in combating the challenges of environmental challenges in developing countries found that dematerialization as one of the key drivers of synergy (Houghton, 2010).

Document dematerialization enabled through enterprise system can fulfill certain critical information security requirements like confidentiality and integrity of communication and data, preventing, detecting and monitoring unauthorized access into the system, proactive backup and support mechanism to foster recovery planning (Mehedintu and Pirvu, 2009).

\section{INFORMATION COMMUNICATION TECHNOLOGY BASED MODEL FOR DEMATERIALIZATION OF ACADEMIC CERTIFICATES}

The proposed model, as shown in Fig. 1, for certificate dematerialization is ICT enabled and has a central repository owned by a central authority. When a student leaves the school and obtains his passing certificate, he is registered with the central authority through the governing body and has a Unique Identification number (UID) allotted to him. The certificate is then digitized and stored in the central repository. When the student joins for higher studies and obtains more certificates, the governing body digitize the same and upload it in central repository. All the certificates belonging to a student will thus have a link to the student UID. Those organizations who would like to verify the academic qualification of a student, can access the central repository via authorized login credentials and obtain details by punching in the student UID.

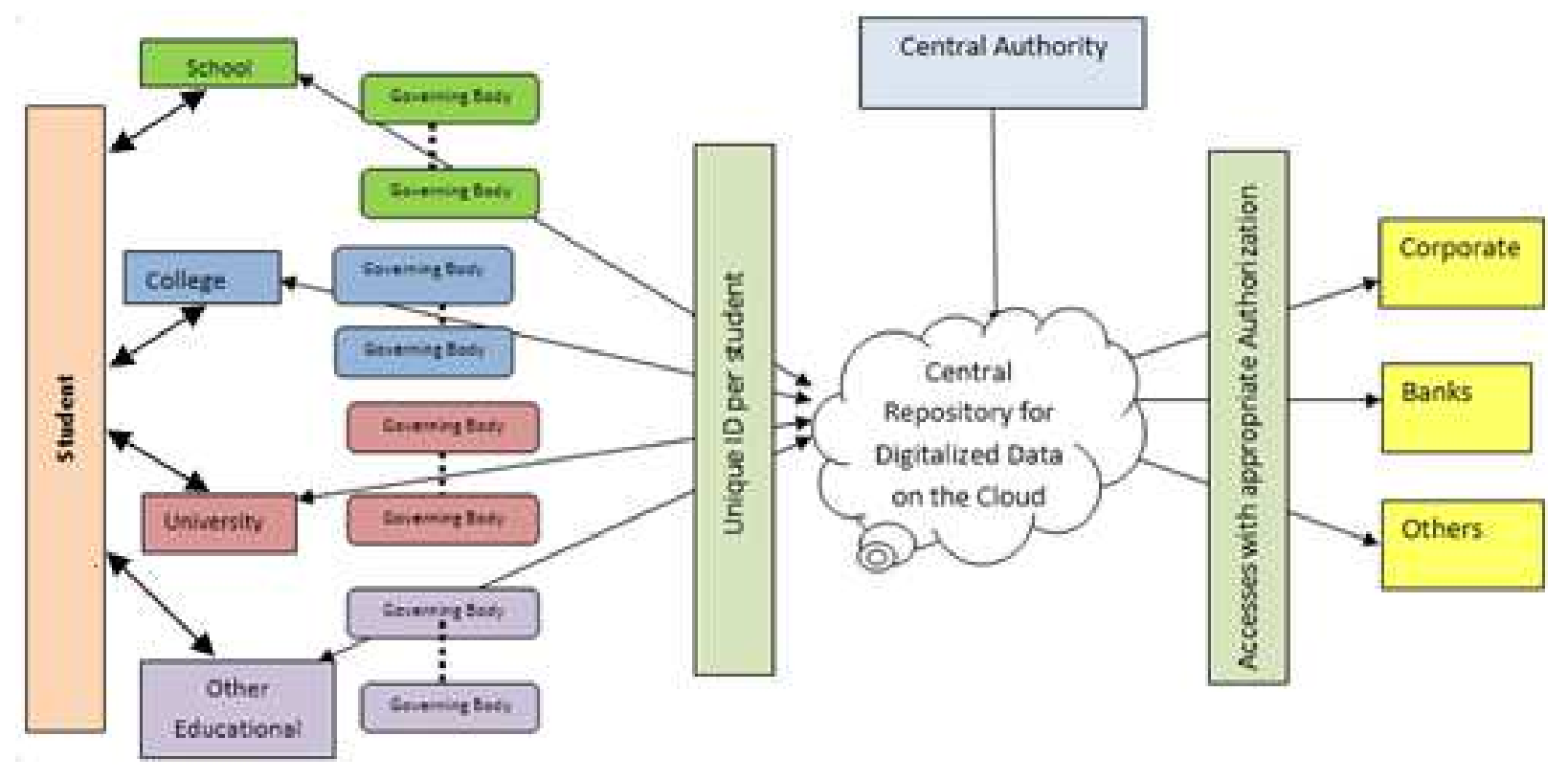

Fig. 1. An ICT based model for dematerialization of a academic certificates 
The proposed model will ensure ease of access to students and provides a secure mechanism for accessing digital certificates. This model if implemented will enable ease of access and provide a standardized mean of verification across the academic eco system and also enable environmental friendly practice at macro level. If this model is compared to the Dematerialization of share in Indian financial services sector, a parallel can be drawn in the following aspects: The governing bodies' roles is similar to the role played by depository participants. The roles of central authority is akin to NSDL and CDSL. The best practice of cloud in terms of infra-structure as a services, platform as a service, software as a service, can be capitalized. The model also has immense advantage in terms of cost benefit if cloud option is resorted to.

The caveat is the academic system requires a different approach for implementing Information systems in a successful manner. Universities are fundamentally different from business organizations in their decision making processes. Consequently the standard IS development strategies developed for business may not be appropriate in institutions of higher education (Heiskanen et al., 2000).

\section{CONSLUSION}

The ICT based model which is proposed above is an all-encompassing one, it enable an end to end process of streamlining and standardizing means to access digital certificates. The current model has limitations which are associated with the cloud based models which include lower degree of security, control and technology as Data is hosted off-site. Public clouds offer generic or cookie-cutter services that are usually not as customizable as an in-house deployment. For example, there is no ability to choose specific hardware components (Carvajal and Chong, 2012). The future scope of work can include a detailed process based roadmap for implementing the digitization project.

\section{REFRENCES}

Berkhout, F. and J. Hertin, 2004. De-materialising and re-materialising: Digital technologies and the environment. Futures, 36: 903-920. DOI: 10.1016/j.futures.2004.01.003

BSL, 2013. What is dematerialisation of shares. Business Standard Ltd.

Carvajal, A. and T. Chong, 2012. Virtualized Business Intelligence with InfoSphere Warehouse. 1st Edn., BM, ISBN-10: 0738437417, pp: 246.

Heiskanen, A., M. Newman and J. Simila, 2000. The social dynamics of software development. Account. Manage. Inform. Technol., 10: 1-32. DOI: 10.1016/S0959-8022(99)00013-2

Houghton, J.W., 2010. ICT and the Environment in Developing Countries: A Review of Opportunities and Developments. In: What Kind of Information Society? Governance, Virtuality, Surveillance, Sustainability, Resilience, Berleur, J.J., M.D. Hercheui and L.M. Hilty (Eds.), Springer, Heidelberg, ISBN-10: 3642154786, pp: 236-247.

IGR, 2012. Indian higher education sector: Opportunities for private participation. IndoGenius Research.

Mehedintu, A. and C. Pirvu, 2009. Enterprise resources planning systems-accountancy support. Dematerialization of the documents. MPRA.

Mirabella, N., L. Rigamonti and S. Scalbi, 2013. Life cycle assessment of information and communication technology application: A case study of dematerialization in the Italian public administration. J. Cleaner Prod., 44: 115-122. DOI: 10.1016/j.jclepro.2012.10.051

Phillip, A., 2005. Higher education in India.

Singh, S., 2011. Depositary system in india-a comparative study of nsdl and cdsl. Int. J. Res. Commun., Econ. Manage., 1: 26-33. 